referred to by $\mathrm{Dr}$ Prescott and his colleagues ${ }^{2} 3$ are unsuitable for patients with mixed poisoning, as it has been established that oxyphenbutazone interferes with the Routh method $^{4}$ and the same drug and others-for example, salicylates and barbiturates-may interfere with the Dordoni procedure. Although, as we stated, measurement of total paracetamol may have been a poor index of the need for treatment, the pretreatment serum alanine aminotransferase (SGPT) values show that many of our patients were severely poisoned.

As to our claims for the efficacy of late cysteamine treatment, Dr Prescott and his colleagues appear to have misread our paper. Our last paragraph states that we do not claim to have proved that cysteamine is effective, only that it is safe. We argue that consideration of the mechanism of its action would lead one to anticipate that cysteamine would prevent further liver damage as long as any unconjugated paracetamol remains in the circulation and there are liver cells still undamaged.

Dr Prescott and his colleagues state that the course of paracetamol poisoning is uninfluenced by cysteamine administered later than $10 \mathrm{~h}$ after overdosage, because it does no change the number of patients who suffer severe liver damage. However, our paper showed, and our current figures confirm, that liver damage was known to be already moderate or severe before treatment in eight out of the 11 patients who developed severe liver damage in the late cysteamine group (see table). Our hypothesis is that cysteamine may prevent these patients progressing to more severe, even fatal liver damage.

Late cysteamine group-current results

\begin{tabular}{c|c|c|c}
\hline $\begin{array}{c}\text { No of } \\
\text { patients }\end{array}$ & $\begin{array}{c}\text { Mean } \\
\text { ingestion- } \\
\text { treatment } \\
\text { interval } \\
\text { (hours) }\end{array}$ & $\begin{array}{c}\text { Severe liver } \\
\text { damage }\end{array}$ & $\begin{array}{c}\text { Death from } \\
\text { fulminant } \\
\text { hepatic } \\
\text { failure }\end{array}$ \\
\hline 20 & $17 \cdot 8$ & $11(55 \%)$ & 0 \\
\hline
\end{tabular}

The numbers in our published series are no large enough to refute or confirm this hypothesis. In the meantime, therefore, we feel that it is entirely reasonable to assume that late cysteamine may indeed protect the liver from further damage. Only series large enough to show significant differences in mortality rates will clarify this point.

We have scrutinised Dr Prescott's list of references but can find no evidence that the lethal potential of cysteamine approaches, let alone exceeds, that of untreated paracetamo poisoning. We find that most of the references state, as we did, that cysteamine is unpleasant. No death has been reported and we feel that slower injection might have prevented the one case of ventricular tachycardia. We have seen no electrocardiographic changes during this regimen.

We should be happy to change to a less unpleasant antidote if any were shown to be equally harmless in patients with severe liver damage. Methionine has been found to induce hepatic coma in some patients with cirrhosis. $N$-acetylcysteine may be as safe as cysteamine in late paracetamol poisoning, but this remains to be proved-the manufacturers are unhappy about its intravenous use. ${ }^{6}$

The Edinburgh workers describe our study as indefensible, but they also used "late" cysteamine in 13 patients. We think their work is readily defensible, although we disagree with their conclusions (for the reasons stated above)

We found their criticism of our preparation of cysteamine confusing, as our "home-made" solutions were prepared according to their own original recipe.?

Finally, we would support the suggestion of James $^{8}$ that a multicentre trial is necessary to determine the effectiveness of any treatmen in reducing the mortality from paracetamol poisoning. Studies of a number of patients developing severe liver damage cannot help us to decide the effectiveness of treatment in a group of patients many of whom have moderate or severe liver damage before treatment is commenced. We need to see significan differences in recovery from this liver damage in the treated and untreated groups. Ou series is as yet too small for this purpose.

A A Gilbertson SyBIL M HaLL

T A WHITE

JENNIFER M SMITH W O ROBERTS

Sefton General Hospital

Liverpool

Glynn, J P, and Kendal, S E, Lancet, 1975, 1, 1147. Dordoni, B, et al, British Medical fournal, 1973, 2, 86. Clinicl Biochemistry, 1976 , and Tan Bha, Annals of

. 15, 93.

Fish, L J, Lancet, 1977, 2, 610.

Prescott, L F, et al, Lancet, 1974, 1, 588 . 1976, 4, suppl 4, p 151 .

**Mercaptamine is preferred to cysteamine both in the WHO's list of recommended international non-proprietary names and in Martindale's Extra Pharmacopoeia. We agree however, that the name cysteamine is much more commonly used in Britain and that the substitution of mercaptamine in the original paper was an error of editorial judgment.-ED, $B M F$.

\section{Cannabis and the cardiovascular system}

SIR,-In the UK cannabis is usually smoked in the form of resin (hashish) mixed with tobacco, in the US as herbal cannabis (marihuana); all the health warnings which refer to tobacco should apply with equal force to these practices. The principal additional physical effects attributable to inhalation of volatile cannabinoids are congestion of the conjunctivae and a dose-related tachycardia, ${ }^{1}$ neither of which seems unduly to concern young smokers. ${ }^{2}$ An average "joint" contains $5 \mathrm{mg}$ of tetrahydrocannabinol (THC), of which approximately half is absorbed and produces a blood concentration of 20-70 $\mu \mathrm{g} / 1 .^{3}$

Much of the work quoted in your leading article (25 February, p 460) refers to herbal cannabis, which contains many active substances. Direct measurement of the mechanical properties of isolated driven papillary cardiac muscle from cat and rat $^{4}$ has shown that THC has a negligible effect on contractile force, its time course, or elasticity in a concentration 1000 times greater than that achieved in man by a smoke. Measurement of these parameters in humans can only be by inference from indirect observation. This is not to deny that smoking herbal cannabis or resin in tobacco will disturb the heart's action by modifying the autonomic regulators, but such an effect is likely to be transitory in persons who do not suffer from disease of the cardiovascular system.

Department of Pharmacology,

J D P GRAHAM

Welsh National School of Medicine

Cardiff

${ }^{1}$ Graham, J D P, and Li, D M F, in Cannabis and Health, ed J D P Graham, pp 162-178. New York,

Graham, J D P, Cannabis Now. Aylesbury, HM and M Publishers, 1977 .

Teale, J D, et al, Lancet, 1974, 2, 553.

raham, J D P, et al, British fournal of Pharmacology

\section{Indomethacin and alclofenac in} rheumatoid arthritis

SIR,-We have recently had occasion to review a summary in our possession of the data relating to a paper reported by $\operatorname{Dr} M$ Aylward and others in the British Medical Fournal. ${ }^{1}$ Although we are of the opinion, through other studies, that alclofenac is efficacious in the treatment of rheumatoid arthritis, we must, with regret, disassociate our company from the above-mentioned publication.

Guildford, Surrey

RONALD D MANN Medical Director

' Aylward M, et al, British Medical fournal, 1975, 2, 7.

\section{Outpatient chemotherapy for breast} cancer

SIR, - We are writing in regard to the paper by Drs J H Goldie and L A Price (22 October, $\mathrm{p}$ 1064) and the subsequent letter from Mr B V Palmer (19 November, p 1354) and the reply from Drs Price and Goldie (17 December, $p$ 1603) regarding the use of methotrexate with folinic acid rescue.

In the past three years we have administered oral high-dose methotrexate $(400 \mathrm{mg})$ with folinic acid rescue on an outpatient basis to 51 patients in a total of 282 courses of treatment. The diagnoses include head and neck cancer, small cell cancer of the lung, breast cancer, lymphatic leukaemia, and lymphoma. The technique requires the patient to take $25 \mathrm{mg}$ ( 10 tablets) of methotrexate every hour for $16 \mathrm{~h}$. The folinic acid is started at $24 \mathrm{~h}$ and continued in a dose of $7.5 \mathrm{mg}$ every $6 \mathrm{~h}$ for a total of eight doses. Parenteral folinic acid $6 \mathrm{mg}$ is given in a single intramuscular injection in the period from 24 to $48 \mathrm{~h}$ and again from 48 to $72 \mathrm{~h}$ in the patient's home by a visiting nurse. No patient has died of the technique and complications have been acceptable. Mucositis occurred in 13 of 215 courses in which methotrexate was the only agent given. Rash occurred in one patient and photosensitivity in another. No patient has had significant neutropenia or thrombocytopenia, and nephrotoxicity has not occurred. Nausea and vomiting is common but rarely severe, and has resulted in abandonment of outpatient treatment in three cases.

The advantage of this approach includes a saving of hospital bed days, reducing the cost of the procedure and the dislocation of the patient's life. The visiting nurse ensures that folinic acid is given even to the patient who may be vomiting. In some cases folinic acid rescue has been extended for several days as a result of the nurse's assessment of the patient on the first visit. We have evidence that with this technique methotrexate blood levels are similar to those achieved with infusions. 
Formulation of a larger-strength methotrexate tablet would permit larger oral doses to be given as we have found that there is a physical limit to the number of tablets which can be taken during one day.

R BELL

J R SULLIVAN

W J MOON

J MARTY

J SHAW

Haemato-oncology Group

Melbourne, Victoria

\section{The battered fetus}

SIR,-May I please inquire through you why it is that the battered fetus seems never to be a subject of concern comparable to the battered baby, the maltreated child, or the battered wife or granny. If the screaming of a young infant is considered provocative to a violent man, then surely so is the gravid uterus, and many battered wives must have had their abdomens attacked during pregnancy by frustrated or suspicious men.

I would like to know if bruising of the abdominal wall is observed during antenatal visits to maternity hospitals as frequently as black eyes are in mothers attending with child outpatients and how often trauma is considered as a contributory cause of antepartum haemorrhage and premature labour. Bizarre congenital deformities of the skeleton such as acute angulation of a tibia, genu recurvatum, or congenital dislocation of a wrist ought to prompt us to inquire about "accidents" such as falls down stairs or motoring injuries, and alternative explanations may be disclosed. It was certainly the opinion of the mothers of two babies whom I have attended that their grotesque tibial deformity was directly associated with extreme violence to the abdomen in mid-pregnancy, and a third mother (with whom I am still in touch) is equally convinced that her daughter's genu recurvatum hip dislocation was associated with an opacity of the sclera and anterior chamber of the eye on the same side as a result of repeated kicks and blows directing the infant's own foot into the eyeball.

It may be that in compiling a comprehensive list of significant "life events" which could have some bearing on the pregnancy we have been too squeamish and should include direct assault with boot or fist.

R J PUGH

Department of Paediatrics,

Hull Royal Infirmary,

Hull, Humberside

\section{Otosclerosis and the operating microscope}

SIR,-I agree with Dr I S Hall (11 February, p 367) that Julius Lempert did not use an operating microscope as I doubt if one existed in the early 'forties. In 1947, in association with Messrs Hutchisons of Edinburgh, I developed an operating microscope, and a description of this was published in the $B M \mathcal{Y} .{ }^{1}$ So far as I am aware this was the first operating microscope used in clinical practice.

The fenestration operation was developed by Maurice Sourdille of France and by Professor Gunnar Holmgren of Stockholm, from whom and his wife I have received great hospitality during visits to Sweden both before and after the war. He must certainly be regarded as the main pioneer of the operation, but I have the impression, more than 30 years later, that, while he used a microscope, this was not an operating microscope but was used for examination of the fenestra after it was made. I do not think that the working distance of his microscope was long enough to allow operative procedures or if there was sufficient illumination. I think that this impression is probably confirmed by the fact that after the publication of my description of the microscope I had a letter from Professor Holmgren's successor, the late Dr Paul Frenckner, asking me where he could obtain an operating microscope. At this time two operating microscopes were being produced in Britain, one by Messrs Beck and the other by Messrs Cook, Troughton, and Simms, of York.

The prototype of the microscope which was developed here has been presented to the museum of the Royal College of Surgeons of Edinburgh.

Edinburgh

A Brownlie Smith

${ }^{1}$ Smith, A B, British Medical fournal, 1947, 1, 776.

\section{"Chickenpox oesophagitis"}

SIR,-The letter from Dr K D Bardhan (11 February, p 370) on oesophageal involvement during chickenpox provided me with some (admittedly) macabre amusement, as well as a sense of relief. Dr Bardhan was unable to find any references to oesophageal involvement in chickenpox, even with the assistance of a computer. Involvement of the oesophagus by varicella was reported in 1940 by Johnson, and the lesions varied from (microscopic) early bullous lesions to massive ulcers. I am relieved that Dr Bardhan, an old friend, recovered since Johnson's report deals with a fatal case and I have had the opportunity, in recent years, to study an almost identical case.

The moral of the story, if one exists, is that computers are not infallible and what you don't know won't hurt.

D J DESA

Department of Pathology Mamalton University,

${ }^{1}$ Johnson, H N, Archives of Pathology, 1940, 30, 292.

\section{Effect of penicillamine after gold treatment}

SIR,-We have long suspected that patients with rheumatoid arthritis (RA) who have previously received gold are under increased risk with side effects from penicillamine. ${ }^{1}$ This patient's case adds weight to our hypothesis.

A 36-year-old woman with definite RA was seen in 1964. She was treated with gold, which produced a remission. The gold had to be stopped after $950 \mathrm{mg}$ because of an itchy maculopapular rash affecting her loins and her lower abdomen anteriorly.

She remained well until 1975, when she again developed pain in her fingers and feet, the fingers starting to be deformed. The fingers and hands showed changes of typical RA, the erythrocyte sedimentation rate being raised at $26 \mathrm{~mm}$ in $1 \mathrm{~h}$ The symptoms remained well controlled with a simple analgesic and anti-inflammatory drugs until June 1976, when she became worse and alclofenac was started. This almost immediately improved her until November 1977, when she became very much worse, with gross swelling of her fingers and ankles. At this stage penicillamine in the small dose of $50 \mathrm{mg}$ daily was substituted for alclofenac.
After 12 days - that is, after a total dose of only $600 \mathrm{mg}$ of penicillamine-she again developed a rash on her trunk which was described as being identical in character and site with the rash which she had experienced on taking gold. The rash took a month to clear; it is of great interest that over that month the RA apparently completely remitted and she returned to full function and was completely free of stiffness when she awakened in the morning.

This clinical situation, although anecdotal, seems to us to be more than a coincidence and we feel it likely that the very small amount of penicillamine that she received had mobilised gold from her tissues which led to the remission.

JoHN GoLDING ALBERT T DAY M A WILSON

Harrogate Royal Bath Hospital,

Harrogate, Yorks

Golding, J R, and Day, A T, British Medical fournal, 1973, 2, 593.

\section{Perhexiline-induced neuropathy}

SIR,-Your leading article on "Drug treatment of chronic stable angina pectoris" (25 February, $p$ 462) rightly emphasises that neurological changes occurring with perhexiline maleate therapy are reversible but that "the ratio of benefit to risk has to be calculated carefully before this effective antianginal drug is prescribed for long-term use."

Our experience of 10 patients with perhexiline-induced neuropathy supports the view that this complication is reversible. The first three patients have previously been described in detail. ${ }^{1}$ The diagnosis was made in each case on the basis of clinical features confirmed by objective tests (nerve conduction velocity and autonomic function tests), with improvement when the drug was withdrawn. Of these 10 patients, eight were men and two women; their ages ranged from 49 to 68 (mean $57 \cdot 8 \pm 5 \cdot 4$ ) years. Perhexiline was prescribed if they were unable to tolerate conventional treatment with beta-blockers or if their anginal symptoms were uncontrolled by this treatment alone. All 10 patients had peripheral neuropathy and five patients in addition had evidence of autonomic neuropathy (postural hypotension, abnormal autonomic function tests). Two patients were taking perhexiline in a dose of $200 \mathrm{mg} /$ day and the remaining eight taking higher doses (300-400 mg/day) The duration of therapy ranged from 3 to 18 (mean $10.3 \pm 5 \cdot 0$ ) months before presentation with neurological impairment.

In all cases the drug was withdrawn and complete recovery occurred over a period of 3-8 months. Clinical recovery was fairly rapid, but return to the normal range of nerve conduction velocity was more prolonged. Only one patient had another condition (diabetes mellitus) which may have contributed to the development of neuropathy, and the features in this patient also reversed on withdrawal of the drug. Two patients have subsequently died from ischaemic heart disease but the other eight remain well. The use of perhexiline in these patients had been successful in controlling severe anginal symptoms initially and there was marked deterioration in symptoms when the drug was withdrawn.

We have used perhexiline now in many cases in similar doses and for prolonged periods without the development of neuropathy. We feel, therefore, that this drug has an important place in the management of patients 